\title{
HISTOLOGIA DA GLÂNDULA DE ALBÚMEN DE POMACEA CANALICULATA (LAMARCK, 1822) (MOLLUSCA, GASTROPODA, PILIDAE)
}

\author{
Eliane de Fátima Marques de Mesquita ${ }^{1}$ \\ Arnaldo Campos dos Santos Coelho ${ }^{2}$ \\ Jefferson Andrade dos Santos ${ }^{3}$
}

\begin{abstract}
In this paper the authors give a histological analysis of the albumen gland of mature and immature females of Pomacea canaliculata (Lamarck, 1822). In the immaturity, tthe gland doesn't show any secretory activity, although in the maturity this activity is indicated by the presence of a homogeneous and eosinophilic material in its lumen. We could notice in the capsule gland of matures females a calcareous element is present as a granular and basophilic deposit. The albumen gland is envolved by a thin conjunctive layer that can be seen in van Gieson's coloured preparations.
\end{abstract}

\section{INTRODUÇÃO}

Com a histologia da glândula de albúmen de fêmeas imaturas e maduras de $P$. $c a$ naliculata, visamos a obtenção de maiores subsídios relativos às técnicas histológicas mais aplicáveis aos moluscos.

\section{MATERIAL E MÉTODOS}

Os espécimes examinados foram capturados em valões próximos à Aléia Frei Leandro, junto ao Lago Principal, Jardim Botânico, Rio de Janeiro; e estão depositados na Coleção Malacológica do Departamento de Invertebrados, do Museu Nacional, Universidade Federal do Rio de Janeiro (COL. MOL. M.N., número 4217, 4218 e lâminas histológicas).

Para a captura dos gastrópodes foi utilizada a técnica direta manual. Após a captu$\mathrm{ra}$, os animais foram mantidos em laboratório à temperatura ambiente que variava entre $20^{\circ} \mathrm{C}$ e $35^{\circ} \mathrm{C}$ dependendo da estação do ano.

Os exemplares foram mantidos em caixas de cimento amianto, tipo Eternit, com capacidade de 50 litros, medindo $50 \mathrm{~cm}$ de comprimento, $31 \mathrm{~cm}$ de largura, $33 \mathrm{~cm}$ de altura, e em cubas de vidro redondas com $13 \mathrm{~cm}$ de diâmetró e $39 \mathrm{~cm}$ de altura, e $29 \mathrm{~cm}$ de diâmetro e $36 \mathrm{~cm}$ de altura. Foram colocadas telas servind o de tampa para que os animais não escapassem.

1. Departamento de Zootecnia, Faculdade de Veterinária, Universidade Federal Fluminense. Parte da Dissertação de Mestrado em Zoologia de E.F.M. Mesquita, aprovada pelo CPG Zoologia do Muse u Nacional, UFRJ em 13.VII.1982.

2. Malacologia, Departamento de Invertebrados, Museu Nacional, Rio de Janeiro.

3. Laboratório de Anatomia Patológica, Faculdade de Veterinária, Universidade Federal Fluminense. 
Para a dissecção, sempre que possível, foram escolhidos os exemplares que apresentavam um tamanho médio que o admitisse como adultos. Retirados da concha por quebra da mesma ou pelo método do "bico-de-gavião" (Lopes, 1956: 535-536) quando desejávemos a não destruição da concha, o animal vivo era então disposto em placa de Petri com fundo de parafina, e umedecido com solução fisiológica $(\mathrm{NaCl}$ a $0,9 \%$ em solução aquosa). A dissecção com a cabeça voltada para o observador, era iniciada com um corte na região látero-dorsal esquerda, na dobra do manto; prosseguíamos com uma incisão circular contornando o saco pulmonar e o rebatimento para a direita do animal, deixando ver imediatamente o aparelho reprodutor feminino, bastante conspícuo.

As dissecçðes dos espécimes foram realizadas sob lupa estereoscópica WILD M4, utilizando-se pinça de ponta bem fina, tesoura tipo oftalmológica e alfinetes entomológicos.

Os exemplares destinados à histologia eram fixados em formol-salina a $5 \%$, sendo neste caso usadas exclusivamente as peças genitais, preservando-se as demais partes em álcool $70^{\circ} \mathrm{GL}$ glicerinado.

Os cortes histológicos, obtidos em micrótomo 820 Spencer, American Optical Corporation, com espessura de $5 \mu \mathrm{m}$, foram corados pela hematoxilina-eosina, de acordo com a técnica de rotina.

Usamos a fixação de fragmentos em formo-salina a 5\% para ulterior coloração especial pelos métodos: Tricrômico de Masson, van Gieson e PAS de acordo com Lillie (1954).

As técnicas de van Gieson e Tricrômico de Masson foram utilizadas para confirmação da presença de fibras musculares lisas e conjuntivas.

A técnica do PAS evidencia a presença de glicoproteínas, mucoproteínas e diferentes tipos de mucopolissacarídeos (Andrews, 1964: 122).

As fotomicrografias foram realizadas com Equipamento Nikon M-35S acoplada ao M.O. WILD LEITZ M20.

\section{RESULTADOS}

\section{Glândula de Albúmen ou Ūtero}

Na imaturidade, se constitui de cordões celulares com células do tipo epitelial dispostas em trabéculas e muitas das quais perfeitamente retilíneas. De permeio, são observadas estruturas arredondadas provindas de luz e revestidas de epitélio simples e do tipo cilíndrico. Seriam os canais condutores da secreção. Ainda não apresenta atividade secretora. Nos condutos mais calibrosos, de luz mais ampla, o epitélio se apresenta também monoestratificado e cilíndrico simples. O duto "principal" tem epitélio cilíndrico simples já apresentando uma camada de tecido muscular liso (Fig. 1). Os dutos presentes nos planos externos da glândula mostram uma estrutura mais complexa, revelando em sua parede a presença de lâminas de tecido muscular liso. Os dutos mais calibrosos se mostram revestidos de epitélio cilíndrico monoestratificado provido de estereocílios, ocorrendo em sua parede fibras musculares lisas. Presença de dutos grandes, médios e pequenos, alguns em forma de fenda. A ausência de sinais de secreção é importante a nível das diferentes porções da glândula. 
Vol. 7(3), 1990

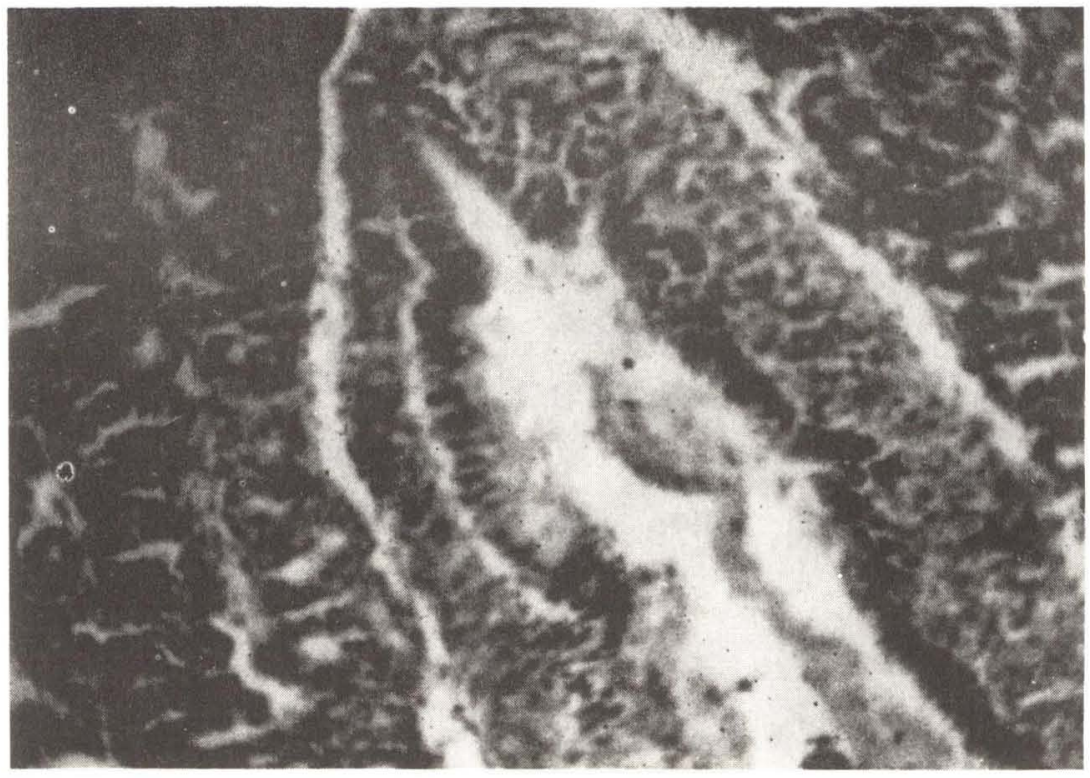

Fig. 1 - Glândula de albúmen em fêmea imatura. Aspecto do duto principal e estroma glandular. HE, aumento $10 \times 15$ (col. Mol. M.N. lote n'. 4217).

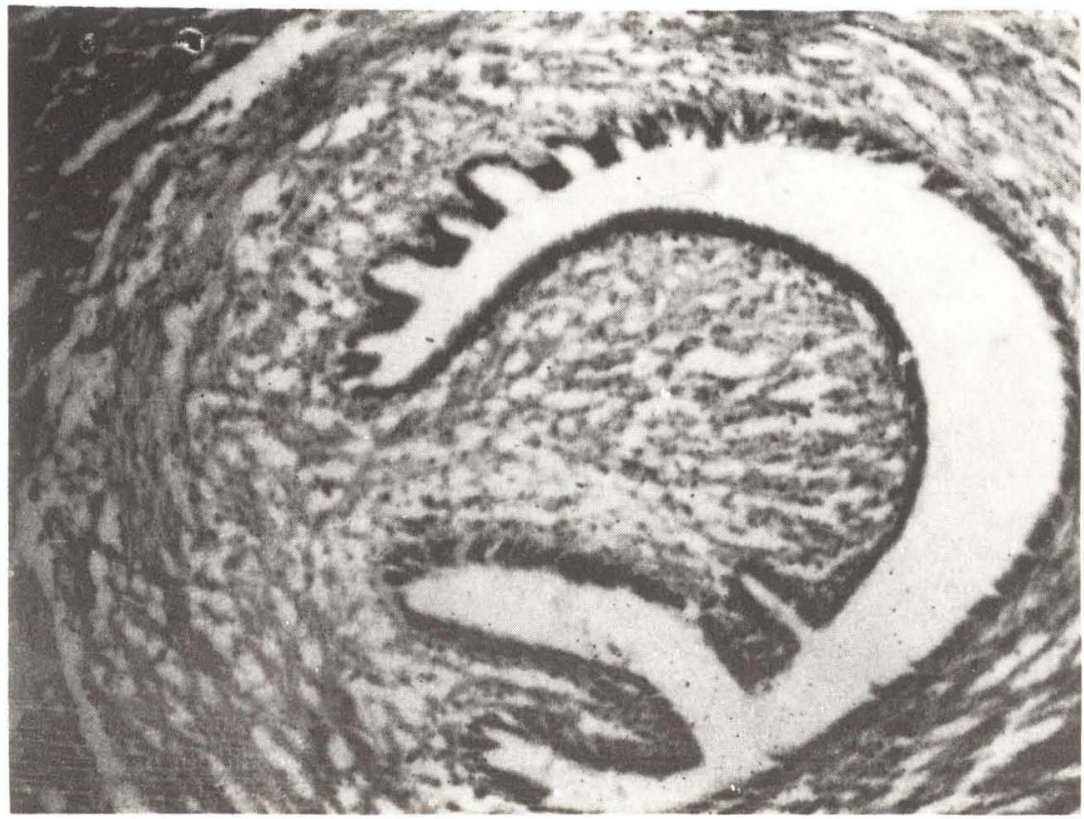

Гig. 2 - Glândula de albúmen em fêmea imatura. Glândula da cápsula e seus dutos. HE, aumento 10 x 15 (col. Mol. M. N. lote n? 4217). 


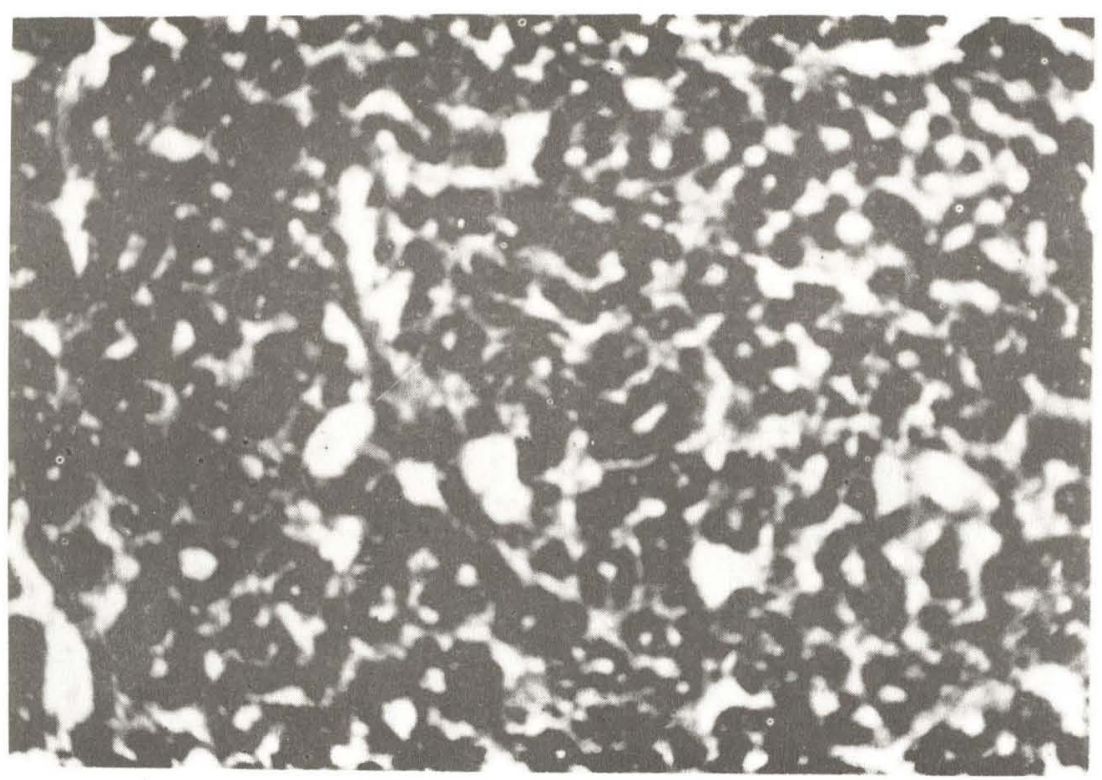

Fig. 3 - Glândula de albúmen em fêmea madura, Coloração pelo PAS, evidenciando a atividade secretora. Aumento $10 \times 15$ (col. Mol. M.N. lote n? 4216).

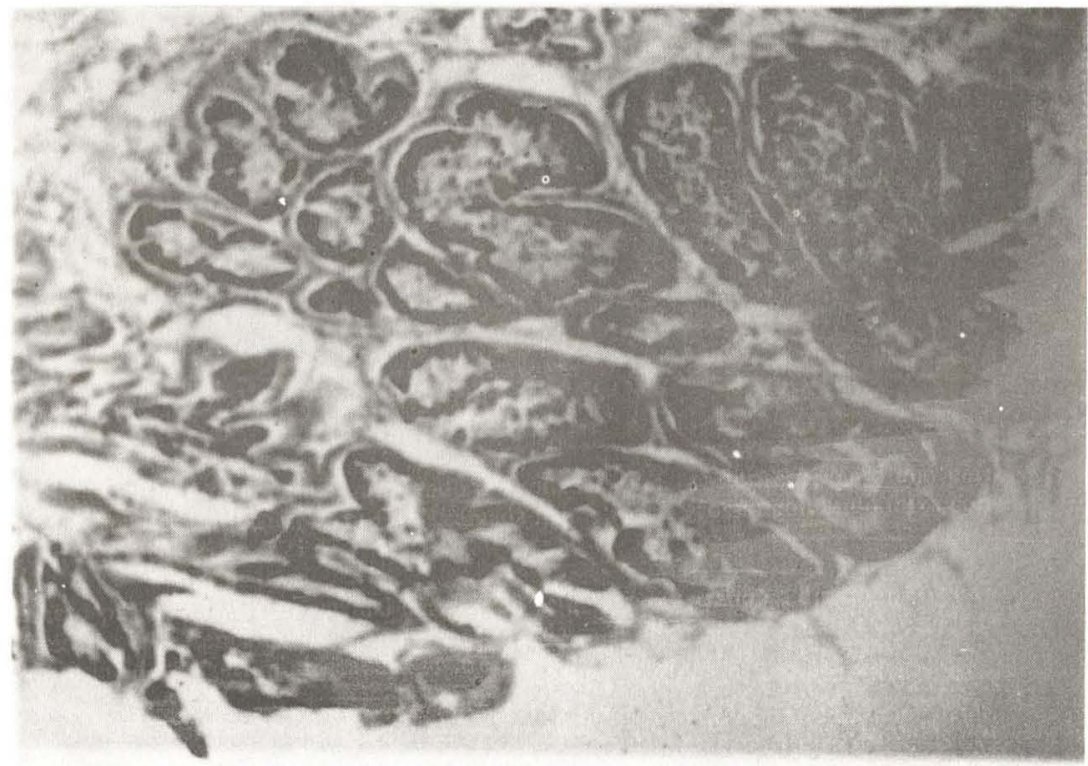

Fig. 4 - Glândula de albúmen em fêmea madura. Depósito de material calcário na glândula da cápsula. HE, aumento $10 \times 15$ (col. Mol. M.N. lote n? 4216). 


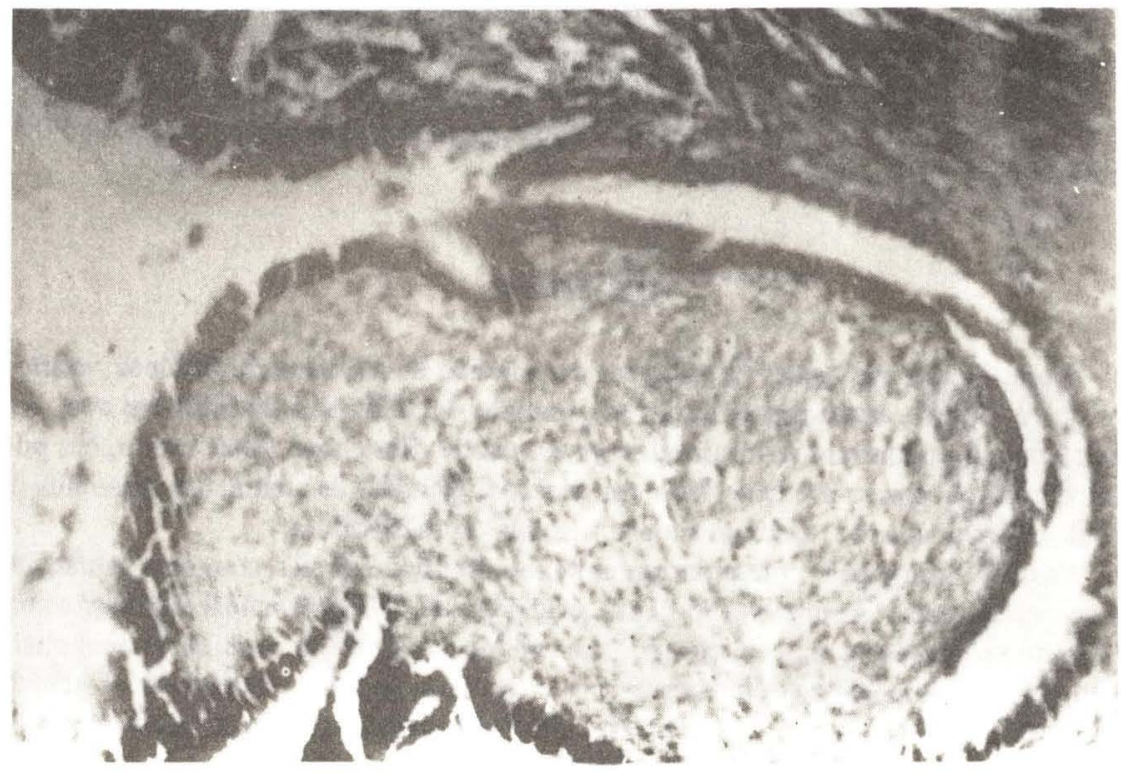

Fig. 5 - Glândula de albúmen. Aspecto do receptáculo seminal em fêmea imatura. HE, aumento 10 \% 15 (col. Mol. M.N. lote n? 4217).

Glândula da cápsula e seus dutos

No seio da glândula se percebe uma estrutura glanduliforme constituída de elementos tubulares de luz relativamente ampla revestidos de epitélio cilíndrico simples com núcleos nitidamente basais. Essas estruturas mostram projeções papilíferas de base relativamente estreita e revestidas de idêntico epitélio (Fig. 2).

Na maturidade, a glândula de albúmen se constitui de elementos celulares acentuadamente basófilos no seu conjunto com disposição ora em cordel, ora acinoso. As células epiteliais apresentam núcleo pouco distinto e aspecto vesicular. É o citoplasma igualmente indistinto assumindo às vezes grupos de células aspectos sinciciais. Há sinais de atividade secretora representados pela ocorrência de material delicadamente homogêneo e delicadamente eosinófilo presente na luz (Fig. 3). Os dutos calibrosos são em forma de fenda, revestidos de epitélio cilíndrico simples e providos de núcleos forte. mente cromáticos e basais.

A glândular da cápsula, estrutura mais complexa, é revestida por elementos de na. tureza fibrilar externa, mostrando a sua mucosa propriamente dita glândulas simples ou lobuladas, percebendo-se o material calcário sob a forma de um depósito granular e fortemente basofilo que se dispõe no fundo de saco. O revestimento epitelial da mucosa é de tipo cilíndrico e delicadamente papilífero o que lhe dá um aspecto eriçado (Fig. 4).

O receptáculo seminal mostra uma parede muscular bastante espessa, a sua luz laminar é revestida de epitélio cilíndrico simples com núcleos basais e fortemente cromáticos. Em outros pontos o epitélio é diferente. Em certas porções, esse epitélio se mostra sensivelmente achatado, assumindo um aspecto laminar (Fig. 5) 
A. glândula de albúmen é envolvida por uma lâmina conjuntiva delgada, perfeitamente evidenciável nas preparações coradas pelo van Gieson.

No parênquima glandular, os elementos fibrilares são inexistentes, ocorrendo como que uma justaposição de ácinos, havendo um perfeito acolamento destes, sem que se observe uma interposição fibrilar.

\section{DISCUSS̃̃O}

Com relação aos coṛtes histológicos da glândula de albúmen em pilídeos, verificamos que a mesma, assemelha-se muito às glândulas de albúmen e da casca nas aves, que nestes animais encontram-se localizadas em estruturas diferentes. Desse modo, em pilídeos, a analogia com a ave seria feita em relação à glândula de albúmen e à glândula da cápsula que, por sua vez, estariam acopladas numa única estrutura.

O duto "principal" apresenta um epitélio cilíndrico simples, com uma camada de tecido muscular liso. Andrews (1964:129) assinalou que o duto principal faz junção com o oviduto, e apresenta um epitélio colunar ciliado com células mucíparas ocasionais. Scott (1957) também fez referência à fina camada muscular circundando o referido duto. Encontramos um revestimento epitelial do tipo cilíndrico simples e delicadamente papilífero, na mucosa da referida glândula.

Andrews (1964: 129) referiu que a parte inicial da glândula da cápsula, inserida no tecido da glândula de albúmen, possui uma escassa camada muscular abaixo de um epitélio ciliado contendo células mucíparas ocasionais. Constatamos que o revestimento epitelial da mucosa da glândula da cápsula é do tipo cilíndrico e delicadamente papilífero, dando-lhe um aspecto eriçado.

Os animais cuja alimentação teve por base ração para peixes de aquário, apresentaram uma fase de maturação mais acelerada e a glândula de albúmen tornou-se muito volumosa e rosada, que nos demais das capturas subseqüentes, alimentados com fragmentos de folhas frescas de alface (Lactuca sativa, familia Compositae). $\mathrm{O}$ inconveniente é que deixa a água turva e leva algum tempo para ser totalmente consumida.

\section{CONCLUSÕES}

1. A glândula de albúmen e da cápsula de Pomacea canaliculata possui uma certa analogia com as glândulas de albúmen e da casca de aves.

2. O tecido conjuntivo tratado pelo Tricrômio de Masson não revelou tão bons resultados quanto o van Gieson.

3. O duto "principal" da glândula de albúmen apresenta um epitélio cilíndrico simples, com uma camada de tecido muscular liso.

4. O revestimento epitelial da mucosa da glândula da cápsula é do tipo cilíndrico e delicadamente papilifero.

5. O PAS evidencia bem a atividade secretora da glândula de albúmen.

6. A aceleração na fase de maturação e aumento no volume da glândula de albúmen, ocorreu em razão do hormônio contido na ração administrada aos animais. 


\section{AGRADECIMENTOS}

Ao Dr. Hugo de Souza Lopes da Academia Brasileira de Ciências, pela orientação prestada e constante incentivo. Ao Professor Eulógio Carlos de Queiroz Carvalho (FV. UFF), pelo trabalho fotográfico realizado sobre as lâminas histológicas. Ao Professor Francisco Carlos de Lima (FV-UFF), pelo auxílio na realização das atividades histológicas. Aos colegas e amigos que nos auxiliaram nas capturas dos animais: Norma Campos Salgado, Hélcio Magalhães Barros e Marcus Vinicius Menezes Ferreira.

\section{REFERENCIAS BIBLIOGRĀFICAS}

ANDREWS, E.B., 1964. The functional anatomy and histology of the reproductive system of some pilid gastropod molluscs. Proc. Malac. Soc. Lond., 36:1 21-140, 4 figs.

LILLIE, R.D., 1954. Histologic technic and practical histochemistry methods. 2nd. ed. New York, Blakiston.

LOPES, H.S., 1956. Sobre Pomacea canaliculata (Lamarck, 1822) (Mesogastropoda, Archietaenioglossa, Mollusca). Rev. Brasil. Biol., 15 (3):375-380, 17 figs.

SCOTT, M.I.H., 1957. Estudio morfologico y taxonomico de los Ampullaridos de la Republica Argentina. Rev. Mus. Argentino Cien. Nat. "Bernardino Rivadavia”. Cien. Zool., 3 (5): 231333, pls. 1-23. 